Ferrata Storti Foundation

\title{
TARP is an immunotherapeutic target in acute myeloid leukemia expressed in the leukemic stem cell compartment
}

Haematologica 2020

Volume 105(5):1306-1316

\section{Correspondence: \\ TIM LAMMENS \\ tim.lammens@ugent.be \\ Received: March 21, 2019. \\ Accepted: July 12, 2019. \\ Pre-published: August 1, 2019.}

doi:10.3324/haematol.2019.222612

Check the online version for the most updated information on this article, online supplements, and information on authorship \& disclosures: www. haematologica.org/content/105/5/1306

(C)2020 Ferrata Storti Foundation

Material published in Haematologica is covered by copyright. All rights are reserved to the Ferrata Storti Foundation. Use of published material is allowed under the following terms and conditions:

https://creativecommons.org/licenses/by-nc/4.0/legalcode. Copies of published material are allowed for personal or internal use. Sharing published material for non-commercial purposes is subject to the following conditions:

https://creativecommons.org/licenses/by-nc/4.0/legalcode, sect. 3. Reproducing and sharing published material for commercial purposes is not allowed without permission in writing from the publisher.

\author{
Barbara Depreter, ${ }^{1,2}$ Karin E. Weening, ${ }^{2,3}$ Karl Vandepoele, ${ }^{2,4}$ Magnus Essand, ${ }^{5}$ \\ Barbara De Moerloose, ${ }^{1,2,6}$ Maria Themeli, ${ }^{7}$ Jacqueline Cloos, ${ }^{7}$ \\ Diana Hanekamp, ${ }^{7}$ Ine Moors, ${ }^{8}$ Inge D'hont, ${ }^{6}$ Barbara Denys, ${ }^{2,4}$ \\ Anne Uyttebroeck, ${ }^{9}$ An Van Damme, ${ }^{10}$ Laurence Dedeken, ${ }^{11}$ \\ Sylvia Snauwaert, ${ }^{12}$ Glenn Goetgeluk, ${ }^{3}$ Stijn De Munter, ${ }^{2,3}$ Tessa Kerre, ${ }^{2,8}$ \\ Bart Vandekerckhove, ${ }^{2,3}$ Tim Lammens ${ }^{1,2 *}$ and Jan Philippé en, $3,4 *^{*}$
}

${ }^{1}$ Department of Internal Medicine and Pediatrics, Ghent University, Ghent, Belgium; ${ }^{2}$ Cancer Research Institute Ghent, Ghent University, Ghent, Belgium; ${ }^{3}$ Department of Diagnostic Sciences, Ghent University, Ghent, Belgium; ${ }^{2}$ Department of Laboratory Medicine, Ghent University Hospital, Ghent, Belgium; ${ }^{5}$ Science for Life Laboratory, Department of Immunology, Genetics and Pathology, Uppsala University, Uppsala, Sweden; ${ }^{6}$ Department of Pediatric Hematology-Oncology and Stem Cell Transplantation, Ghent University Hospital, Ghent, Belgium; 'Department of Hematology, VU University Medical Center, Amsterdam, the Netherlands; ${ }^{8}$ Department of Hematology, Ghent University Hospital, Ghent, Belgium; ${ }^{9}$ Department of Pediatrics, University Hospital Gasthuisberg, Louvain, Belgium; ${ }^{10}$ Department of Pediatric Hematology Oncology, University Hospital Saint-Luc, Brussels, Belgium; ${ }^{11}$ Department of Pediatric Hematology Oncology, Queen Fabiola Children's University Hospital, Brussels, Belgium and ${ }^{12}$ Department of Hematology, AZ Sint-Jan Hospital Bruges, Bruges, Belgium

*JP and TL contributed equally to this work as co-senior authors.

\section{ABSTRACT}

Trmart mmunotherapeutic strategies targeting the rare leukemic stem cell compartment might provide salvage to the high relapse rates currently observed in acute myeloid leukemia (AML). We applied gene expression profiling for comparison of leukemic blasts and leukemic stem cells with their normal counterparts. Here, we show that the T-cell receptor $\gamma$ chain alternate reading frame protein (TARP) is over-expressed in de novo pediatric $(\mathrm{n}=13)$ and adult $(\mathrm{n}=17)$ AML sorted leukemic stem cells and blasts compared to hematopoietic stem cells and normal myeloblasts (15 healthy controls). Moreover, TARP expression was significantly associated with a fmslike tyrosine kinase receptor-3 internal tandem duplication in pediatric AML. TARP overexpression was confirmed in AML cell lines $(n=9)$, and was found to be absent in B-cell acute lymphocytic leukemia $(n=5)$ and chronic myeloid leukemia $(n=1)$. Sequencing revealed that both a classical TARP transcript, as described in breast and prostate adenocarcinoma, and an AML-specific alternative TARP transcript, were present. Protein expression levels mostly matched transcript levels. TARP was shown to reside in the cytoplasmic compartment and showed sporadic endoplasmic reticulum co-localization. TARP-T-cell receptor engineered cytotoxic T-cells in vitro killed AML cell lines and patient leukemic cells co-expressing TARP and HLA-A*0201. In conclusion, TARP qualifies as a relevant target for immunotherapeutic T-cell therapy in AML.

\section{Introduction}

Acute myeloid leukemia (AML) is a heterogeneous hematologic malignancy, accounting for $80 \%$ of adult ${ }^{1.4}$ and $20 \%$ of pediatric ${ }^{5.7}$ leukemia. Despite initial clinical remission rates of $60-90 \%, 2,5,6$ patients exhibit a high relapse risk and therapyrelated mortality, resulting in a 5 -year overall survival of $30 \%$ in adult $\mathrm{AML}^{1,3}$ and $65-70 \%$ in pediatric AML (pedAML), ${ }^{5,8}$ Especially the prognosis of patients with fms-like tyrosine kinase receptor-3 internal tandem duplications (FLT3-ITD) remains extremely poor. ${ }^{2,8,9}$ The high relapse rate is thought to arise from a chemotherapy-resistant cell fraction with unlimited self-renewal capacities, 
denominated as leukemic stem cells (LSC). ${ }^{4,10-14}$ In CD34 ${ }^{+}$ AML, stem cell characteristics were shown to be present in all four CD34/CD38 phenotypic compartments, though the $\mathrm{CD} 34^{+} \mathrm{CD} 38^{-}$fraction was the most LSC-enriched. ${ }^{15}$ Moreover, a high LSC load at diagnosis was shown to be a significant adverse prognostic factor. ${ }^{16-19}$ Unfortunately, current chemotherapeutic regimens were shown to perform inadequate towards LSC eradication ${ }^{14}$ and they induce important toxicity. ${ }^{5,6,20}$ Also hematopoietic stem cell transplantation, performed in high-risk (HR) patients or as salvage therapy, carries a high mortality and morbidity risk, ${ }^{2,5}$ highlighting the need for alternative treatments. Thus, identifying LSC aberrations is crucial to tackle the high relapse rate and to develop therapeutic targeting strategies for LSC elimination, while ensuring salvage of normal hematopoietic stem cells (HSC).

Targeted therapy has led to remarkable progress in the survival rates of multiple cancers. The introduction of tyrosine kinase inhibitors in the treatment of chronic myeloid leukemia (CML) accomplished a major breakthrough, and CD19-directed chimeric antigen receptor (CAR) therapy has led to an enormous improvement in survival in relapsed/refractory pediatric ALL. ${ }^{21,22}$ These successes paved the way for the exploration of the clinical applicability of targeting antibodies and CAR- or T-cell receptor (TCR)-transgenic cytotoxic $\mathrm{T}$ cells (CTL) in AML.,23-28 Although an increasing number of LSC-specific membrane markers have been identified over recent years, ${ }^{18,23,29,30}$ only a few reports address the molecular abnormalities of LSC compared to HSC, ${ }^{15,31-37}$ especially in pedAML.

Here, we identified the $\mathrm{T}$-cell receptor (TCR) $\gamma$ chain alternate reading frame protein (TARP) as an AML-specific target, expressed in the LSC and blasts of pediatric and adult AML, while absent in their normal counterparts. TARP transcript expression was associated with FLT3-ITD in pedAML. In addition, we provide in vitro evidence that TARP may serve as a novel immunotherapeutic target in AML for TARP-TCR engineered CTL.

\section{Methods}

\section{Patients}

We retrospectively selected diagnostic material from 13 pedAML and 17 adult AML patients based on the sample availability, LSC load, CD34 positivity, FLT3 mutational status, and HLA-status (Table 1 and Online Supplementary Table S1). At diagnosis, mononuclear cells (MNC) were isolated from bone marrow (BM) or peripheral blood (PB) by Ficoll density gradient (Axisshield) and cryopreserved in 90\% fetal calf serum (FCS) and 10\% dimethylsulfoxide (DMSO). Samples were thawed, followed by 30 minutes ( $\mathrm{min}$ ) incubation at room temperature (RT) in $20 \mathrm{~mL}$ RPMI with $20 \%$ FCS, $200 \mu \mathrm{L}$ DNase I $(1 \mathrm{mg} / \mathrm{mL}$, grade II bovine pancreas), and $200 \mu \mathrm{L} \mathrm{MgCl2} \mathrm{(1} \mathrm{M)} \mathrm{(Sigma-Aldrich).} \mathrm{After} \mathrm{incuba-}$ tion, cells were spinoculated (10 min, $400 \mathrm{rpm}$ ) and washed once more with RPMI $/ 20 \%$ FCS.

In addition, we prospectively collected material from 15 healthy subjects. Normal bone marrow (NBM, $\mathrm{n}=6$ ) was collected from posterior iliac crest of pediatric patients (4-18 years) undergoing scoliosis surgery. Umbilical cord blood $(\mathrm{CB}, \mathrm{n}=7$ ) was obtained after normal vaginal deliveries at full term. Mobilized peripheral blood stem cells (mPBSC, $n=2$ ) were collected by apheresis of adult donors pre-allotransplant. All patients or their guardians gave their informed consent and approval was obtained by the ethical committee, in accordance with the Declaration of Helsinki. Buffy coats from donors were obtained from the Red Cross (Mechelen, Belgium) and used for CTL isolation and the preparation of feeder cell medium.

\section{Flow cytometry analysis and cell sorting}

Cell pellets were surface stained (Online Supplementary Table S2), followed by $20 \mathrm{~min}$ incubation at $4^{\circ} \mathrm{C}$ and washing with $\mathrm{PBS}^{+} 2 \%$ BSA. For cell-sorting, labeled cells were resuspended in medium and sorted on a FACSAria III with red, blue, and violet lasers (BD Biosciences). For flow cytometry (FCM) analysis, cells were resuspended in PBS $+2 \%$ BSA and analyzed on a LSR II or a FACSCanto II, equipped with four or three solid-state lasers, respectively (both BD Biosciences). All scatters were devoid of doublets based on FSC-H/FSC-A, and propidium iodide (PI) was used to exclude dead cells. Sorting strategies are described in Online Supplementary Data 2.2. Regarding FCM-based cytotoxicity and cytokine assays (Online Supplementary Data 2.9), living cells were selected using a LIVE/DEAD staining (1:10000 dilution, ThermoFisher Scientific) instead of PI. Target cells were stained with a Violet CellTrace ${ }^{\mathrm{TM}}$ (VT) Cell Proliferation Kit (5 mM, 1:10000 dilution, ThermoFisher Scientific) prior to incubation with TCR-engineered CTL. After incubation and before surface staining, Flow-Count ${ }^{\mathrm{TM}}$ Fluorospheres (1:20 diluted, Beckman Coulter) were added to each well to enable target quantification (measurement of minimum 1000 Fluorospheres/well).

\section{Transcript expression}

Details on micro-array profiling, RNA isolation, cDNA synthesis, quantitative polymerase chain reaction (qPCR) conditions and primers can be found in Online Supplementary Data 2.3, 2.4, 2.5 and Online Supplementary Table S3. qPCR data analysis was performed according to state-of-the-art methods. ${ }^{38,39}$ Relative quantity (RQ) values were normalized against housekeeping genes GAPD, HPRT1 and TBP. For TARP expression, normalized relative quantities were calibrated (calibrated normalized relative quantity, $\mathrm{CNRQ}$ ) versus a single calibrator to allow interrun comparison. For the investigation of the subcellular localization of TARP, delta (d) Ct between cytoplasmic and nuclear compartments were calculated and compared to MALAT1 and TBP expression. Functional TCRG gene rearrangements were excluded if sufficient material remained using DNA TCRG GeneScan analysis40 and/or TRGV(J)C qPCR (Online Supplementary Table S4).

\section{Protein detection}

Details on western blotting and confocal microscopy are provided in Online Supplementary Data 2.6.

\section{Viral transduction of acute myeloid leukemia cell lines and generation of T-cell receptor-transgenic cytotoxic T cells}

All transfer and helper plasmids used, and procedures for transformation, plasmid isolation, transfection and transduction are described in Online Supplementary Data 2.7 and 2.8.

Six AML cell lines (HL-60, Kg-1a, MOLM-13, HL-60-Luc, MOLM-13-Luc and MV4;11-Luc) were transduced with HLA$\mathrm{A}^{*} 0201 \mathrm{MHC}-\mathrm{I}$ encoding retrovirus, hereafter defined as A2+. Transgenic TARP overexpression (OE) cell lines were generated for OCI-AML3 and THP-1, next to mock controls. TARP was knocked down in four TARP-high AML cell lines (HL-60, Kg-1a, MV4;11 and THP-1) using three different shRNA, next to mock controls.

TARP-TCR engineered CTL were generated by transduction with lentiviral (LV) or retroviral (RV) particles encoding a TCRA8T2A-TCRB12 sequence directed against the HLA-A*0201-restrict- 
Table 1. Characteristics of de novo acute myeloid leukemia (AML) patients used for sorting $\mathrm{CD} 34^{+} \mathrm{CD} 38^{+}$and $\mathrm{CD} 4^{+} \mathrm{CD} 38^{-}$cell fractions and qualitative polymerase chain reaction evaluation.

\begin{tabular}{|c|c|c|}
\hline & $\begin{array}{c}\text { Pediatric AML ( } n=13 \text { ) } \\
\text { Median (Range) }\end{array}$ & $\begin{array}{c}\text { Adult AML ( } n=17 \text { ) } \\
\text { Median (Range) }\end{array}$ \\
\hline Age, years & $10(2-16)$ & $48(20-76)$ \\
\hline WBC count, $x 10^{\circ} / \mathrm{L}$ & $66(2.7-336)$ & $15(6-274)^{\dagger}$ \\
\hline \multicolumn{3}{|c|}{ Morphological blast count } \\
\hline $\mathrm{BM}, \%$ & $81(34-96)$ & $77(28-90)^{\dagger}$ \\
\hline $\mathrm{PB}, \%$ & $67(1-95)$ & $73(7-93)^{\|}$ \\
\hline
\end{tabular}

Gender

$\begin{array}{lllll}\mathrm{F} & 7 & 53.8 \% & 9 & 52.9 \% \\ \mathrm{M} & 6 & 46.2 \% & 8 & 47.1 \%\end{array}$

Sample
BM
PB

CD34 positivity

Fusion transcript

CBF leukemia

WT1 overexpression

Mutation status

$\begin{array}{lcccc}\text { NPM1 } & 0 & 0.0 \% & 5^{\ddagger} & 35.7 \% \\ \text { FLT3-ITD } & 8 & 61.5 \% & 9^{\dagger} & 60.0 \%\end{array}$

Risk classification

\begin{tabular}{lcccc} 
SR & 7 & $53.8 \%$ & Favorable & $423.5 \%$ \\
HR & 5 & $38.5 \%$ & Intermediate-I/II & $741.2 \%$ \\
Unknown & 1 & $7.7 \%$ & Adverse & $317.6 \%$ \\
& & & Unknown & $317.6 \%$ \\
\hline
\end{tabular}

Pediatric acute myeloid leukemia (pedAML) patients were diagnosed in Belgium and treated according to the DB AML-01 ( $\mathrm{n}=9,69 \%$ ) or NOPHO-DBH AML 2012 ( $=4,31 \%$ ) protocol. Pediatric patients were risk stratified as previously published ${ }^{8}$ and categorized according to the French-American-British (FAB) classification into M0 ( $\mathrm{n}=1$ ), M1 ( $\mathrm{n}=1$ ), M2 $(n=4)$, M3 ( $n=1)$, M4 ( $n=3)$, M5 ( $n=2)$, and M7 $(n=1)$. Adult AML samples were from patients treated at the Ghent University Hospital, Ghent, Belgium ( $n=12,71 \%)$ or VUmc, Amsterdam, the Netherlands $(\mathrm{n}=5,29 \%$ ). Belgian patients were treated according to local and international guidelines, whereas Dutch patients were included in the HOVON $102(\mathrm{n}=3)$ or HOVON $132(\mathrm{n}=2)$ study. Adults were risk stratified according to the European LeukemiaNet 2010 guidelines ${ }^{1}$ and categorized according to the FAB classification into M1 ( $\mathrm{n}=6), \mathrm{M} 2(\mathrm{n}=6)$, and M3 ( $\mathrm{n}=2)$. WT1 overexpression was interpreted according to in-house or published cut-offs. Core binding factor (CBF)-positive leukemias comprised AML with $\mathrm{t}(8 ; 21)(\mathrm{q} 22 ; \mathrm{q} 22)$ (pedAML=3) and inv(16)(p13q22) (pedAML=1, adult AML=2). Other fusion transcripts detected were DEK-NUP214 (pedAML=1) and PML-RARA (pedAML=1, adult AML=1). *One, 'two, three or "five missing data. BM: bone marrow; F: female; M: male; NPM1: nucleophosmin; PB: peripheral blood; WBC: white blood cell; WT1:Wilms' tumor 1.

ed synthetic TARP peptide TARP(P5L). ${ }^{4-13}$ Regarding RV transduced TARP-TCR CTL, mock CTL were used to correct for non-TARP mediated lysis, and CMV-TCR transduced CTL to evaluate aspecific killing.

\section{Results}

\section{Discovery of T-cell receptor $\gamma$ chain alternate reading frame protein transcript expression in acute myeloid leukemia}

In order to identify LSC-specific antigens, we re-analyzed the gene set enrichment (GSE) 17054 micro-array dataset from Majeti et al., ${ }^{31}$ which included gene expression profiles of $\mathrm{CD} 34^{+} \mathrm{CD} 38^{-}$sorted fractions of four healthy adults (HSC) and nine adult AML patients (LSC). $T A R P$ ranked first amongst the top differentially expressed genes, with all four probes in the top 20 (range log2-FC 5.13-6.92), showing a significantly higher expression in LSC compared to HSC $(P<0.01)$ (Online Supplementary Figure S1). TARP had previously been identified as a truncated TCR transcript expressed in androgen-sensitive prostate and breast adenocarcinoma (Online Supplementary Figure S2). ${ }^{41,42}$ We further explored TARP expression in pedAML by micro-array profiling $\mathrm{CD}_{3} 4^{+} \mathrm{CD} 38^{+}(\mathrm{n}=4$, leukemic blast) and $\mathrm{CD}^{+} 4^{+} \mathrm{CD} 38^{-}(\mathrm{n}=3$, LSC) sorted cell populations from four pedAML patients (2 FLT3-ITD and 2 FLT3 WT) (Online Supplementary Table S1). In addition, sorted $\mathrm{CD}_{3} 4^{+} \mathrm{CD} 38^{+}(\mathrm{n}=3)$ and $\mathrm{CD} 34^{+} \mathrm{CD} 38-(\mathrm{n}=2)$ cells from $\mathrm{CB}$ were profiled to examine the expression in their normal counterparts (Online Supplementary Figure S3). TARP appeared to be more highly expressed in leukemic blasts and LSC from FLT3-ITD patients compared to FLT3 WT patients and CB (Figure 1A). This finding suggested that TARP might represent a LSC-associated target within HR pedAML patients harboring FLT3-ITD.

To validate these data in a larger patient group, we sorted $\mathrm{CD} 34^{+} \mathrm{CD}_{38}{ }^{+}$and $\mathrm{CD} 34^{+} \mathrm{CD} 38^{-}$cell populations from nine additional pedAML (resulting in a total of 13 pedAML patients), 17 adult AML (Table 1) and 15 control samples ( $\mathrm{n}=7 \mathrm{CB}, \mathrm{n}=6 \mathrm{NBM}, \mathrm{n}=2 \mathrm{mPBSC}$ ). qPCR analysis using TARP short primers (Online Supplementary Table S3 and Online Supplementary Figure S2) showed that TARP transcripts were consistently low in HSC and myeloblasts 
A

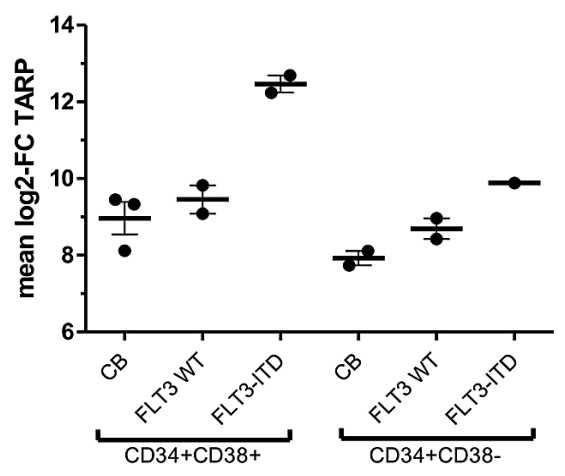

C
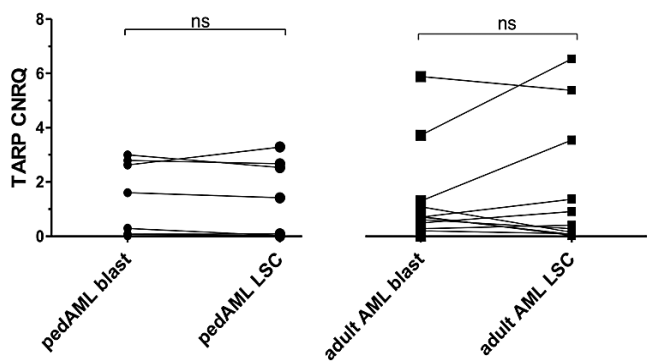

$E$

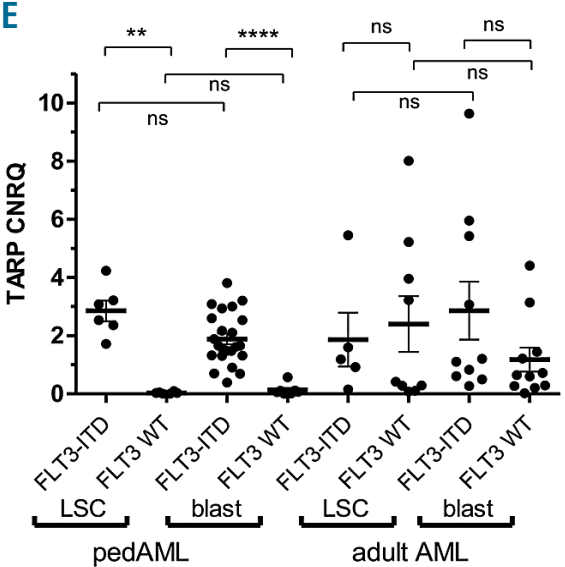

G

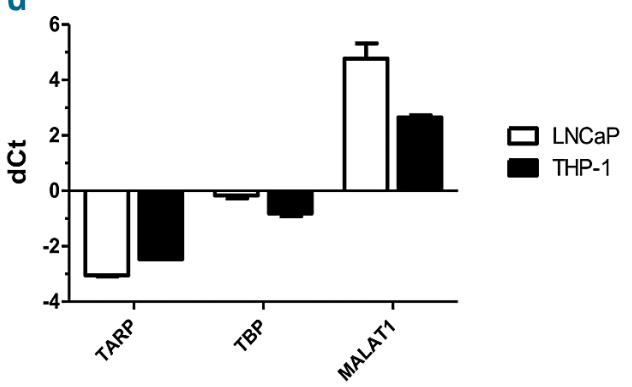

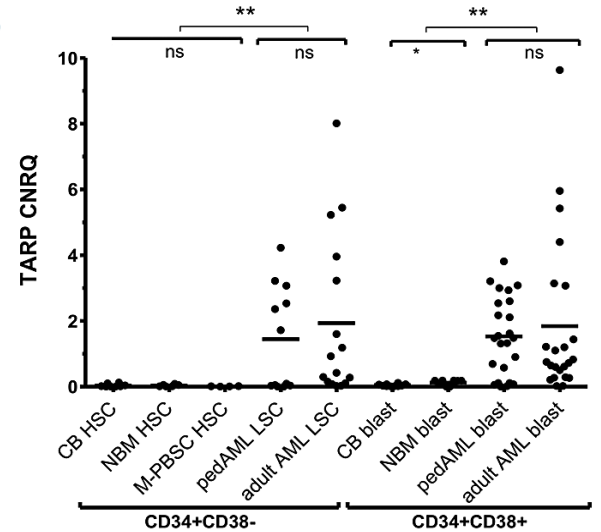

D

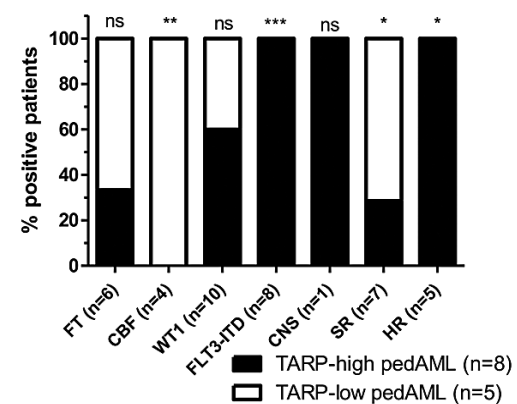

$\mathbf{F}$

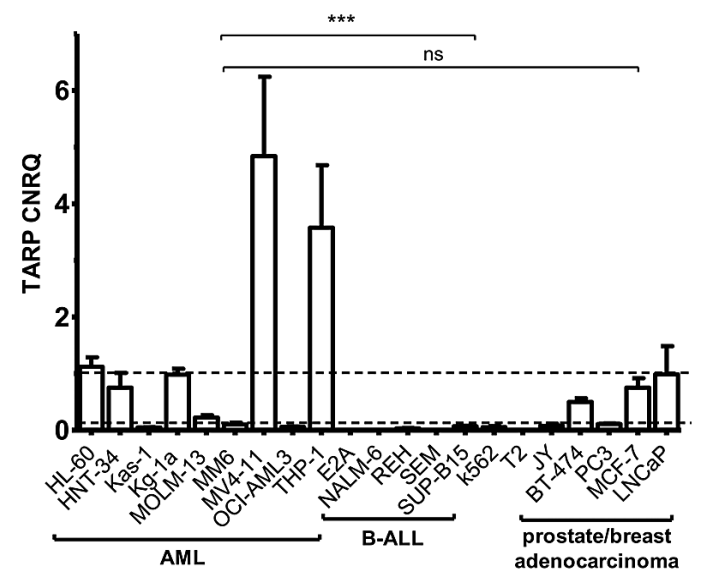

Figure 1. T-cell receptor $\gamma$ chain alternate reading frame protein (TARP) transcript expression in pediatric acute myeloid leukemia (pedAML) and adult AML leukemic cells and cell lines. For TARP qualitative polymerase chain reaction (qPCR), (CNRQ) values were calculated using LNCaP (prostate adenocarcinoma cell line) as interrun calibrator. Biological replicates, e.g. cells sorted from the same patient in different runs and independent cDNA syntheses, were depicted as independent data points. Horizontal bars ind cate meansand error bars indicate meantsta cate means and resent statistical was determined in $\mathrm{CD} 34^{+} \mathrm{CD} 38^{+}(n=4)$ and $\mathrm{CD} 34^{+} \mathrm{CD} 38^{-}(\mathrm{n}=3)$ cell fractions from four pedAML patients $(2$ FLT3-ITD, 2 FLT3 WT) (Online Supplementary Table S1) by micro-array profiling. Sorted $\mathrm{CD} 34^{+} \mathrm{CD} 38^{+}(\mathrm{n}=3)$ and CD34 ${ }^{+}$D 38- $(n=2)$ cord blood (CB) cells were used as control populations. Mean log2-FC values ( $y$ axis) were calculated based on both TARP probes included in the array, the $x$-axis represents the different sample groups. (B) TARP expression was significantly higher in CD34+CD38 and $\mathrm{CD}^{+} 4^{+} \mathrm{CD} 38^{+}$cell fractions from $A M L$ patients (13 pedAML and 17 adult $A M L)$ compared to healthy controls ( $7 \mathrm{CB}, 6 \mathrm{NBM}$ and 2 mPBSC) (P<0.01, Mann Whitney U test). Blasts from NBM show a marginally higher expression pared to CB $(P=0.049)$. (C) Comparison of TARP expression between leukemic stem cells (LSC) and blasts within pedAML (circles, $n=10$ ) and adult AML (squares, $n=12$ ) on a per patient basis showed no significant differences $(P>0.05$, paired sample $t$-test). ( $D$ ) Bars display the percentage of patients (\%), harboring the characteristic shown in the $\mathrm{x}$-axis (dichotomous variables, for details see Table 1), for TARP-high (black, $\mathrm{n}=8$ ) and TARP-low (white, $\mathrm{n}=5$ ) pedAML patients. The total number of patients positive for each characteristic is shown between parentheses. Patients without central nervous system (CNS) involvement all showed negative lumbar punctures. Data on CNS involvement and risk profile is lacking for one patient. The number of patients harboring FLT3-ITD ( $P<0.001)$ and HR profiles $(P<0.05)$ were significantly higher in the TARP-high group, whereas TARP-low pedAML patients included significantly more CBF-leukemia $(P<0.01)$ and SR profiles $(P<0.05)\left(\chi^{2}\right.$ test). (E) Differential TARP expression between LSC and blasts sorted from pediatric and adult AML patients with FLT3-ITD versus FLT3 WT. A significant higher TARP expression in LSC $(P<0.01)$ and blasts $(P<0.0001)$ was only detected for FLT3-ITD positive pedAML patients (Mann Whitney U test). (F) TARP expression in nine AML cell lines, five B-ALL cell lines, the CML cell line K562, the Epstein-Barr virus (EBV)-immortalized B-cell line JY and T2 cell line, next to two breast (BT-474, MCF-7) and two prostate (LNCaP, PC3) adenocarcinoma cell lines. Dashed lines indicate the expression observed in PC3 and LNCaP, serving as low and high reference, respectively, in agreement with previous literature. ${ }^{41}(\mathrm{G})$ Delta (d) Ct values were calculated for TARP, MALAT1 and TBP between cytoplasmic and nuclear compartments of THP-1 and LNCaP, in order to examine the subcellular location of TARP. THP-1 showed a cytoplasmic residence for TARP, in agreement with LNCaP. FC: fold change; FT: fusion transcript; Kas-1: Kasumi-1; MM-6: MONOMAC6; mPBSC: mobilized peripheral blood stem cells; NBM: normal bone marrow. 
A

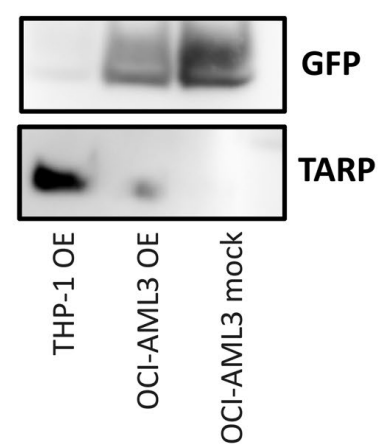

c
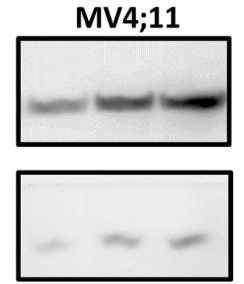

5

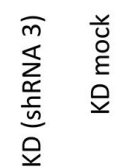

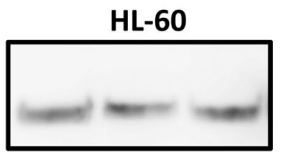

B
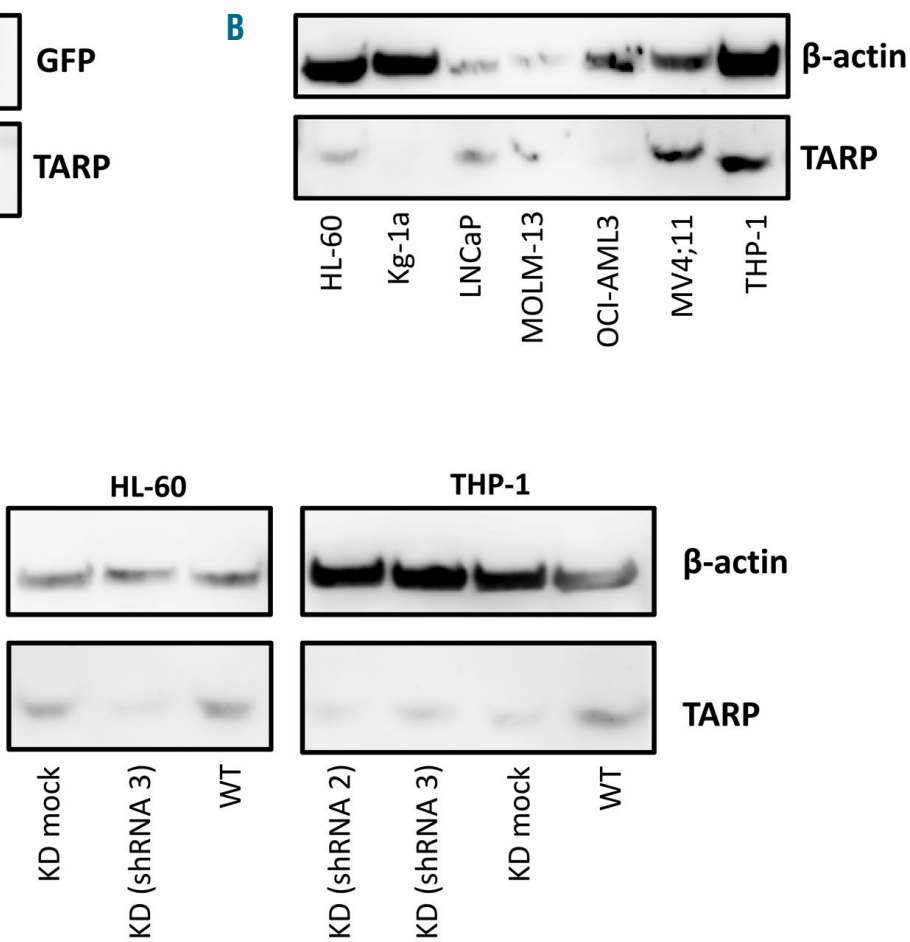

$\beta$-actin

TARP

Figure 2. T-cell receptor $\gamma$ chain alternate reading frame protein (TARP) expression in cell lines evaluated by western blotting. Whole-blot images with ladders used for size estimation are shown in Online Supplementary Figure S7. (A) TARP transgenic (OE) cell lines generated for OCl-AML3 and THP-1 showed a 27 kDa protein for GFP and a 15-25 kDa protein for TARP. In agreement with low TARP transcript levels, the OCl-AML3 mock cell line only showed a $27 \mathrm{kDa}$ GFP protein. TARP expression in THP-1 OE was higher than OCI-AML3 OE, most likely resulting from both transgenic and cognate TARP protein expression, since THP-1 was categorized by qualitative polymerase chain reaction (qPCR) as a TARP-high acute myeloid leukemia (AML) cell line. (B) Immunoblotting of TARP and $\beta$-actin in AML cell lines (HL60, Kg-1a, MOLM-13, OCl-AML3, MV4;11 and THP-1) next to LNCaP. Protein expression mostly matched transcript levels, except for Kg-1a, although confocal microscopy did allow TARP protein staining in Kg-1a. $\beta$-actin expression appeared to be lower for LNCaP and MOLM-13, although equal amounts of protein were loaded. (C) Immunoblotting of TARP and $\beta$-actin in selected shRNA-mediated knockdown (KD) AML cell lines for MV4;11, HL-60 and THP-1, next to their respective mock and wild-type (WT) cell line. For HL-60, a stable knockdown was introduced by shRNA 3 (19.4\% compared to mock). KD: knockdown; OE: overexpression.

sorted from $\mathrm{CB}, \mathrm{NBM}$ and $\mathrm{mPBSC}$ (Figure 1B), although blasts from NBM showed a marginally higher expression compared to $\mathrm{CB}$ (mean $\mathrm{CNRO} 0.12$ vs. $0.045, P=0.049$ ). In sharp contrast, LSC and blasts from pediatric and adult AML showed significantly $(P<0.01)$ higher expressions compared to their normal counterparts. Paired comparison between LSC and blasts on a per patient basis showed no significant differences (Figure 1C).

A cut-off for elevated TARP expression was determined based on the highest expression in control fractions plus two times the standard deviation. Classification of patients into TARP-high (8 pedAML, 13 adult AML) and TARP-low (5 pedAML, 4 adult AML) revealed that FLT3-ITD $(P<0.001)$, CNS involvement and HR profile $(P<0.05)$ were exclusively present in TARP-high pedAML patients (Figure 1D). TARP expression was shown to be significantly higher in sorted LSC $(P<0.01)$ and blasts $(P<0.0001)$ from FLT3-ITD compared to FLT3 WT pedAML (Figure $2 \mathrm{E}$ ). In adult AML, high TARP expression was not restricted to FLT3-ITD. On the other hand, all pediatric (Figure 1D) and adult (Online Supplementary Figure S4A) core-binding factor (CBF) leukemia were classified as TARP-low patients $(P<0.01)$. TARP-low pedAML patients were included in the standard risk (SR) groups $(P<0.05)$. No significant differences in age, white blood cell (WBC) count, or blast percentages were observed between TARP-high and -low pediatric or adult AML patients (Online Supplementary Figure S4B and C). We thus conclude that TARP is highly and specifically expressed in AML leukemic cells from both adults and children, showing a significant association with FLT3-ITD in pedAML.

Next, we evaluated TARP transcript levels in cell lines of various origin. Expression in breast and prostate adenocarcinoma (PC3, BT-474, LNCaP and MCF-7) was in agreement with previous findings ${ }^{42}$ (Figure 1F). No expression was detected in five B-ALL cell lines, CML cell line K562, EBV-immortalized B-cell line JY and T2 cell line. Expression in AML cell lines, on the other hand, was significantly increased $(P<0.001$, one-way ANOVA). The highest expression was observed in HL-60, HNT-34, Kg1a, MV4;11 and THP-1 (median CNRQ 1.12, range 0.754.84), whereas low transcript levels were observed in Kas1, MOLM-13, MONO-MAC6 and OCI-AML3 (median CNRQ 0.080, range 0.049-0.22). Furthermore, fractionation revealed a mainly cytoplasmic localization of TARP mRNA in THP-1 (Figure 1G), as previously shown in LNCaP43.

To evaluate whether the TARP transcript detected in AML is identical to previous reports, we sequenced the TRGC region of different TARP amplicons obtained by qPCR for AML cell lines and pedAML leukemic cells. Using TARP long primers, we observed a single band for 


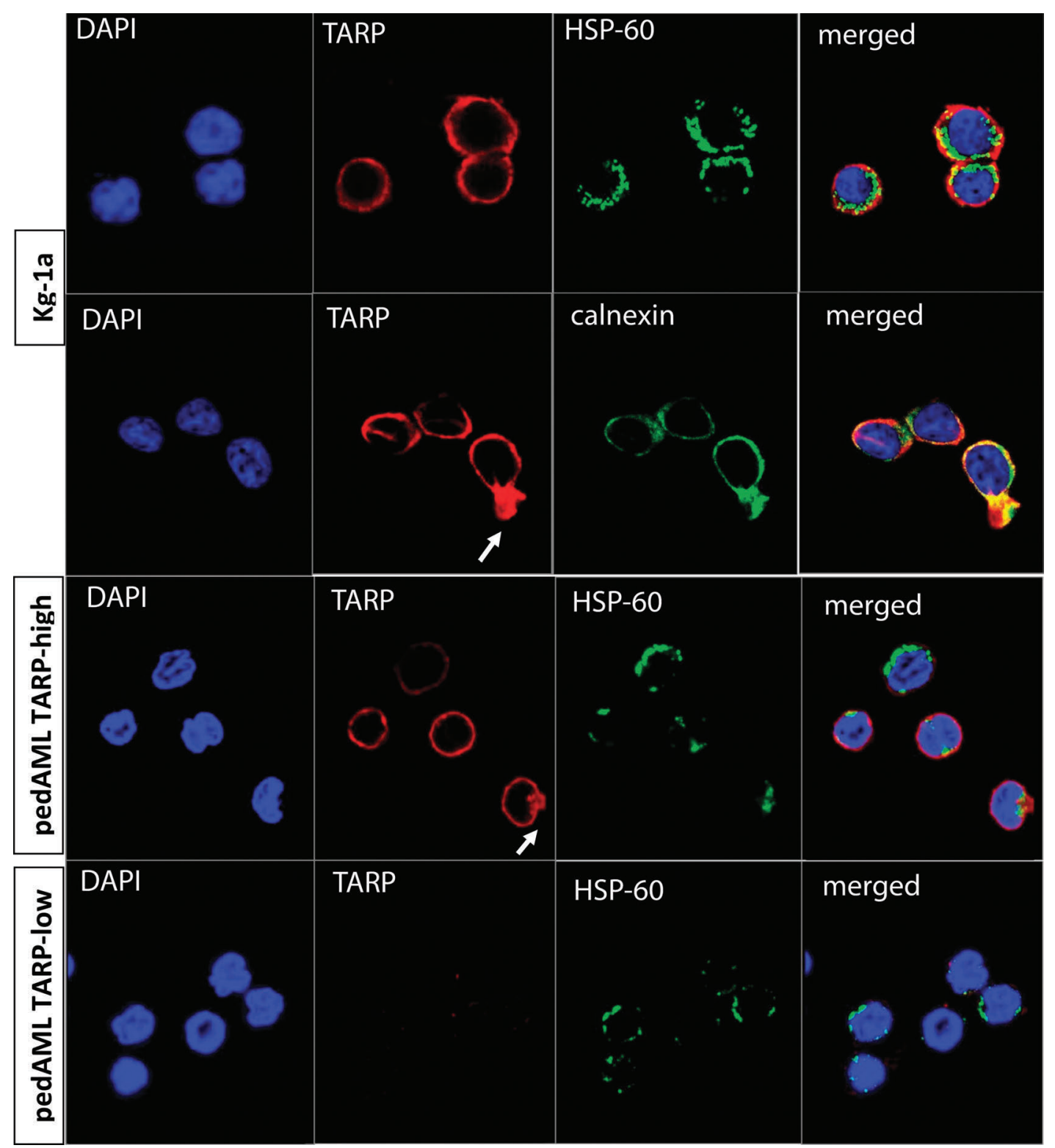

Figure 3. T-cell receptor y chain alternate reading frame protein (TARP) protein detection in Kg-1a and patient leukemic cells by confocal microscopy. Merged patterns visualize TARP (red) and HSP-60 (top lane) or calnexin (bottom lane) (both in green) co-localization (yellow fusion signals) together with DAPI nuclear counterstaining (blue). Leukemic cells were sorted from two pediatric acute myeloid leukemia (pedAML) patients, classified as TARP-high and TARP-low by qualitative polymerase chain reaction. Calnexin staining was not performed on primary cells due to lack of material. Within Kg-1a and the sorted TARP-high leukemic cells, TARP expression was enriched at the cells' protrusions, indicated by arrows.

Kg-1a, which was similar to the LNCaP and TRGC1 reference sequence (Online Supplementary Figure S5A). Unexpectedly, three fragments were observed in the sorted blasts and LSC from TARP-high pedAML patients and the MV4:11 cell line. Cloning and sequencing of each fragment (Online Supplementary Figure S5B) revealed that the largest fragments were artificial heteroduplexes, ${ }^{44}$ whereas the smallest fragments were identical to the fragments from Kg-1a and LNCaP. Medium-sized fragments were consistently $48 \mathrm{bp}$ longer, and showed the same size as the HSB-2 amplicon, a T-cell acute lymphoblastic leukemia (T-ALL) cell line with functional TRGC2 rearrangements. ${ }^{45}$ As TRGC2 contains a duplicated second exon (48 bp) compared to TRGC145 (Online Supplementary Figure S2), we hypothesized that there might be an alternative TARP transcript in AML. Indeed, most AML cell lines, but none of the prostate and breast adenocarcinoma cell lines, showed TRGC1 as well as TRGC2 amplicons (Online Supplementary Figure S5C and E). Single bands for exon 3 and exon 1 amplicons in all cell lines provided evidence that the occurrence of the second transcript is related to the TRGC2 duplicated second exon. Altogether, TARP was highly expressed in approximately half of the AML cell lines evaluated, and both TRGC1- and TRGC2related transcripts co-existed in AML. 
A

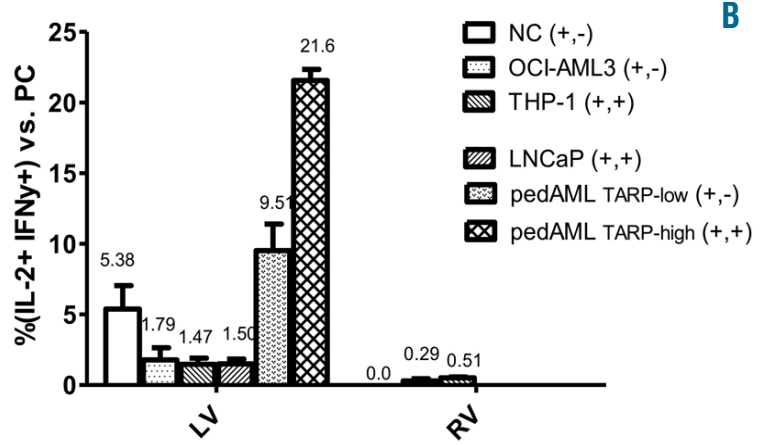

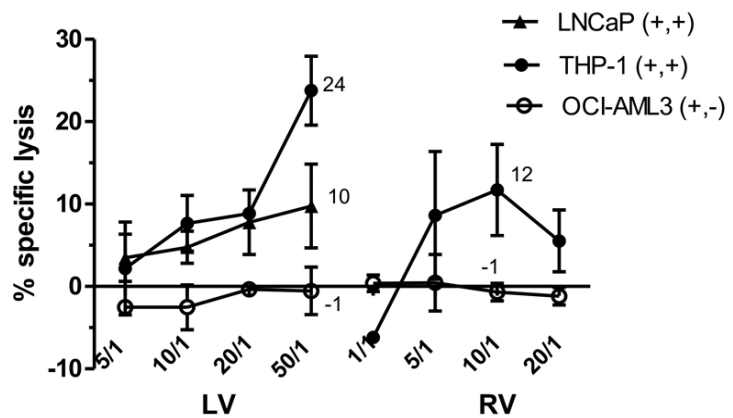

C

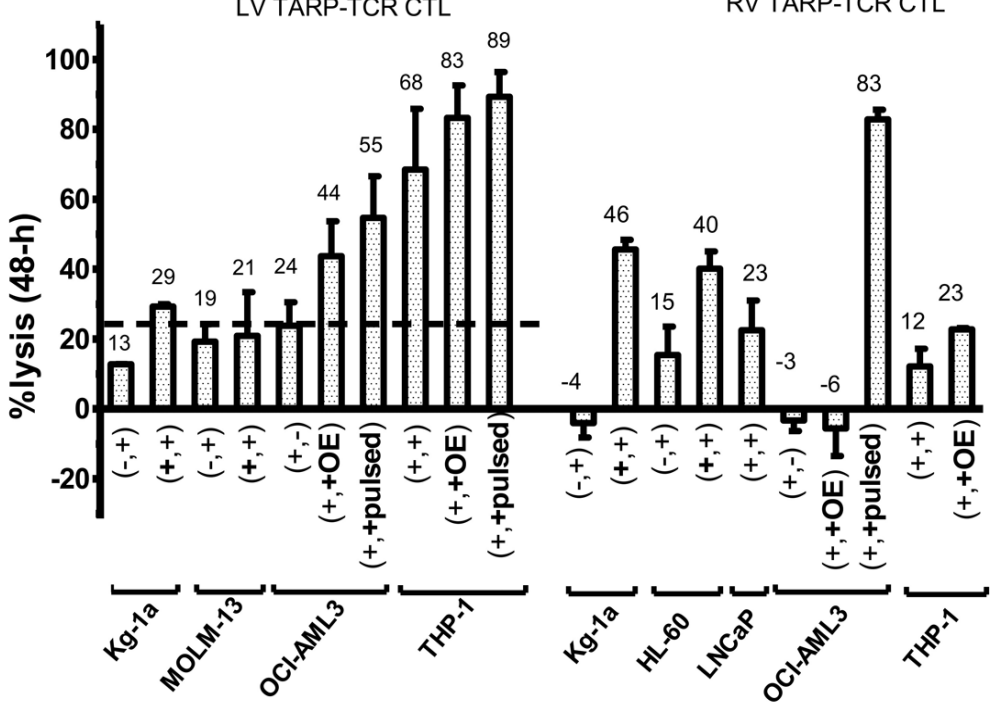

D

$\mathbf{E}$
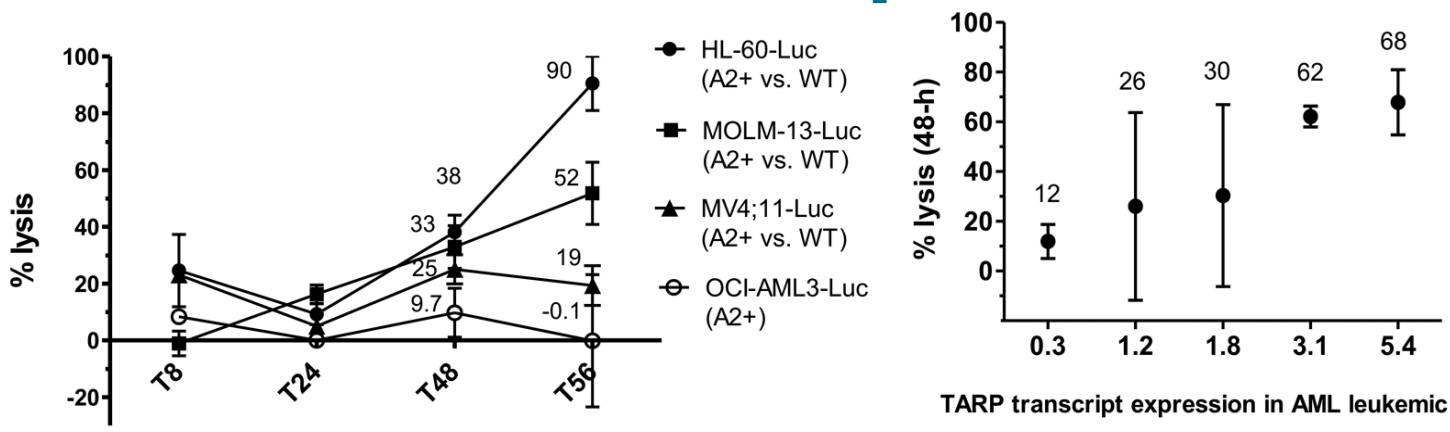

TARP transcript expression in AML leukemic cells

Figure 4. Functional evaluation of T-cell receptor (TCR)-transgenic cytotoxic T cells (CTL) towards cognate and modified cell lines and patient leukemic cells. (A) Cytokine response (IFN- $\gamma / \mathrm{IL}-2$ expression within the $\mathrm{CD}^{+} / \mathrm{CD} 8^{+}$compartment) by co-incubation ( 1 hour, h) with OCl-AML3 and THP-1 was evaluated by both lentiviral (LV) and retroviral (RV) TCR-T-cell receptor y chain alternate reading frame protein (TARP) CTL. LNCaP and patient leukemic cells (single experiment) were only evaluated by LV transduced TARP-TCR CTL. For each target, positive (+) or negative (-) HLA-A*0201 and TARP expression, in this respective order, is indicated between brackets. HLA-A*0201 and TARP co-expressing cell lines (LNCaP and THP-1) were unable to trigger higher cytokine release than OCl-AML3 with low TARP expression. Leukemic cells from a TARP-high pediatric acute myeloid leukemia (pedAML) patient triggered a 2-fold higher cytokine release compared to a TARP-low pedAML patient. (B) Lytic response of LV and RV TARP-TCR CTL versus HLA-A*0201-positive TARP-high (black symbols) and TARP-low (white symbols) targets, measured by a chromium ${ }^{51}$ release assay after $4 \mathrm{~h}$. Highest lysis of TARP-high cell lines was observed at E/T ratio 50/1 for LV and 10/1 for RV TARP-TCR CTL (percentages indicated between brackets), whereas OCl-AML3 (HLA-A*0201 ${ }^{+}$, TARP-) remained unaffected. (C) Lytic response of LV and RV TARP-TCR CTL versus towards wild-type (WT), transgenic and pulsed AML cell lines, measured by a 48-h FCM-based cytotoxicity assay. The dashed line indicates the highest level of non-TARP mediated background killing observed for LV TARP-TCR CTL, as no mock CTL could be constructed. Positive (+) or negative (-) expression for HLA-A*0201 and TARP is shown, in this respective order, between brackets. Bold symbols indicate the expression differing from wild-type, either by retroviral transduction or pulsing. HLA-A*0201 transgenic AML cell lines were more efficiently lysed compared to their HLA-A*0201-negative counterparts (Kg-1a, MOLM-13, HL-60). Higher lysis was observed for transgenic TARP OE or peptide-pulsed cell lines compared to the WT cell line (OCI-AML3, THP-1), except for killing of TARP OE OCI-AML3 cell line by RV TARP-TCR CTL. (D) Lysis by LV TARP-TCR CTL, measured at different time points ( $8 \mathrm{~h}, 24 \mathrm{~h}, 48 \mathrm{~h}$ and $56 \mathrm{~h}$, as indicated on x-axis), based on the luminescence release by transgenic $\mathrm{HLA}$ - $\mathrm{A} * 0201$ expressing TARP-high AML cell lines with respect to the HLA-A*0201 WT cell line (HL-60-Luc, MOLM-13-Luc and MV4;11-Luc: black symbols). In addition, lysis of the TARP-low, cognate HLA-A*0201-positive OCl-AML3 cell line was evaluated (white symbols). Mean lysis (\%) observed after $48 \mathrm{~h}$ is indicated next to whiskers, representing the mean \pm standard error of mean. (E) 48-h FCM-based cytotoxicity assay evaluating lysis of primary leukemic cells (adult AML=5, all FLT3-ITD mutated) by LV TARP-TCR transduced CTL (biological duplicates). TARP transcript expression (CNRQ) is shown in the $x$-axis for each target. IFN- $\gamma$ : interferon gamma; IL-2: interleukin-2; INF: influenza. 
T-cell receptor $\gamma$ chain alternate reading frame protein is expressed in acute myeloid leukemia cell lines and patient leukemic cells

We generated TARP transgenic cell lines in order to optimize western blot experiments and evaluate TARP protein expression in AML. THP-1 and OCI-AML3 OE cell lines showed a significant higher TARP transcript expression $(P<0.01)$ compared to mock controls (Online Supplementary Figure S6A). Western blotting confirmed presence of TARP and GFP proteins in both $\mathrm{OE}$ cell lines, with a size of around $20 \mathrm{kDa}$ and $27 \mathrm{kDa}$, respectively (Figure $2 \mathrm{~A}$ and Online Supplementary Figure S7). Concordantly, the OCIAML3 mock cell line, negative for TARP, only showed a 27 kDa GFP protein. WT AML cell lines HL-60, MV4;11, THP-1 and MOLM-13, as well as LNCaP, also showed a $20 \mathrm{kDa}$ TARP protein, with expression corresponding to the transcript levels (Figure 2B and Online Supplementary Figure S7). TARP knockdown (KD) cell lines were generated for HL-60, Kg-1a, MV4;11 and THP-1 using TARP-targeting shRNA, next to mock controls. Transcript levels were efficiently down-regulated (Online Supplementary Figure S8), and KD cell lines for HL-60, MV4;11 and THP1 showing the highest transcript downregulation were selected for western blotting (Figure 2C and Online Supplementary Figure S7). Protein levels were efficiently down-regulated in HL-60 transduced with shRNA 3 (19.4\% compared to mock). This downregulation was less clear in MV4;11 and THP-1: 116\% (shRNA 3) and 108\% (shRNA 3) versus $63 \%$ (shRNA 2), respectively.

To confirm western blot data and determine the subcellular location of TARP, confocal microscopy was performed using TARP antibodies combined with mitochondrial (HSP-60) and endoplasmic reticulum (ER, calnexin) staining. The over-expressing OCI-AML3 and THP-1 cell lines (Online Supplementary Figure S6B and C) and TARPhigh WT AML cell lines showed a perinuclear membranous-type TARP staining pattern (Kg-1a (Figure 3), HL-60, MV4;11 and THP-1 (Online Supplementary Figure S9). This finding was in contrast to the barrel-shaped TARP pattern with mitochondrial co-localization reported in LNCaP.43 Co-localization with calnexin, presenting as a speckled pattern throughout the ER, was more abundant in some cell lines, e.g. Kg-1a, showing TARP enrichment at the cells' protrusions. TARP-low cell lines concordantly showed weak or negative TARP protein staining (Online Supplementary Figure S8). Importantly, the leukemic cells sorted from a TARP-high and TARP-low pedAML patient also illustrated differential TARP protein expression in agreement with the transcript levels, again showing limited mitochondrial overlap (Figure 3).

\section{T-cell receptor $\gamma$ chain alternate reading frame protein transgenic cytotoxic T cells display specific anti-leukemic activity}

To explore if TARP might represent an immunotherapeutic target in AML, we evaluated the cytokine and cytotoxicity response of TARP-TCR transgenic CTL, encoding a previously developed TCRA8-T2A-TCRB12 sequence targeting the HLA-A2 enhanced affinity TARP(P5L) ${ }_{4-13}$ epitope. ${ }^{46,47}$ As concomitant HLA-A*0201 and TARP expression is required to trigger TCR-mediated killing, HLA-A*0201 transgenic cell lines were generated for 3 WT cell lines (HL-60, Kg-1a and MOLM-13) and 3 Luc-positive cell lines (HL-60-Luc, MOLM-13-Luc, MV4;11-Luc).

First, target specificity of the TARP-TCR was examined in a non-competitive environment using T2 cells (endogenous HLA-A*0201+) pulsed with exogenous peptides (Online Supplementary Table S3). As expected, we found stronger cytokine responses (Online Supplementary Figure $S 10 A$ ) and higher killing rates (Online Supplementary Figure $S 10 B$ and $C$ ) towards the TARP(P5L $)_{413}$ than to the cognate $\mathrm{TARP}_{4.13}$ peptide for both RV and LV transduced CTL, with LV TARP-TCR CTL generally reacting stronger. T2 cells pulsed with non-TARP-related peptides (INF, CMV) were not affected, although CMV-pulsed T2 cells were efficiently recognized by CMV-TCR CTL, indicating a high specificity of the TARP-TCR.

Second, we explored the immunogenicity of cell lines with endogenous HLA-A*0201 presentation. Exposure to LNCaP and THP-1 appeared to be insufficient to trigger cytokine release for both LV and RV transduced TARPTCR CTL (Figure 4A). Using a chromium ${ }^{51}$ release assay, we observed a lytic response by LV transduced TARP-TCR CTL starting from effector to target ratio (E/T) 10/1, with a maximal average response at 50/1 (LNCaP 10\%, THP-1 $24 \%$ ), whereas RV transduced TARP-TCR CTL performed best at 10/1 (THP-1 12\%) (Figure 4B). The TARP-low AML cell line OCI-AML3 remained unaffected under all conditions. Altogether, as the TARP-TCR targets the enhanced HLA-A2 TARP(P5L) 4.13 $_{3}$ binding peptide, we observed weaker responses against endogenous TARP-expressing cell lines compared to pulsed T2 cells.

Third, lysis of TARP-high HLA-A*0201-negative cell lines was evaluated versus their HLA-A*0201 transgenic counterparts in a 48-h FCM-cytotoxicity assay. In addition, killing of TARP transgenic or TARP-pulsed HLA$A^{*} 0201$-positive cell lines was compared to the respective TARP-low WT cell line (Figure 4C). A non-TARP mediated lysis by LV TARP-TCR CTL of maximal $20 \%$ was observed (indicated by dashed line). Stable transduction of HLA-A*0201 increased killing for Kg-1a compared to the WT cell line (29\% vs. $13 \%$ ), whereas killing of MOLM-13, with lower TARP expression levels, remained unaffected when HLA-A*0201 was introduced. Transgenic TARP OE and TARP(P5L) ${ }_{4-13}$ pulsed OCI-AML3 cells were prone to a higher lysis than the WT cell line $(44 \%$ and $55 \%$, respectively, vs. 24\%). Killing of TARP OE/pulsed THP-1 cells was only marginally up-regulated, most likely due to an already high endogenous expression. These data were confirmed using RV TARP-TCR CTL, and corrected for non-TARP mediated lysis using mock CTL. HLA-A*0201 expression again increased killing of $\mathrm{Kg}-1 \mathrm{a}(46 \%$ vs. $-4 \%)$ and HL-60 (40\% vs. $15 \%)$ compared to the WT cell line. Up-regulated killing of transgenic TARP OE THP-1 cells was again limited. For OCI-AML3, lysis was up-regulated after pulsing, but remained low for the TARP OE transgenic cell line. Killing by LV TARP-TCR CTL was additionally evaluated in a bioluminescence imaging (BLI)based assay using Luc-positive AML cell lines with high TARP expression (HL-60 and MV4;11) and low TARP expression (MOLM-13 and OCI-AML3) (Figure 4D). A higher lysis was observed for HL-60-Luc and MV4;11-Luc when expressing HLA-A*0201 at $48 \mathrm{~h}$ and $56 \mathrm{~h}$, indicating that also in long-term cytotoxicity experiments HLAA*0201 restricted TARP-specific killing could be detected.

Finally, we explored the feasibility of therapeutic targeting of primary leukemic cells by LV TARP-TCR CTL. Coincubation with blasts sorted from a TARP-high pedAML patient resulted into a 2 -fold higher IFN- $\gamma$ and IL-2 production compared to a TARP-low pedAML patient $(22 \%$ 
vs. 10\%) (Figure 4A). Moreover, TARP-TCR CTL were also capable of killing leukemic cells from de novo adult AML patients $(n=5)$ (Figure 4E). Lysis ranged between $12 \%$ and $68 \%$, and borderline correlated to TARP transcript levels (Spearman's coefficient $0.82, P=0.089$ ).

\section{Discussion}

We demonstrated increased TARP expression in AML LSC $\left(\mathrm{CD} 34^{+} \mathrm{CD} 38^{-}\right)$and blasts $\left(\mathrm{CD} 34^{+} \mathrm{CD} 38^{+}\right)$from primary patients compared to their normal counterparts as well as AML cell lines. We also showed that TARP protein is expressed in primary AML leukemic cells and are adequately presented on HLA molecules, which makes the cells targetable for immunotherapy.

TARP expression has only been investigated in prostate tissue and androgen-sensitive prostate adenocarcinoma and breast adenocarcinoma, ${ }^{42,43,48}$ next to a single report on salivary adenoid cystic carcinoma. ${ }^{49} \mathrm{We}$ found that TARP expression was significantly $(P<0.001)$ higher in FLT3ITD compared to FLT3 WT pedAML patients at diagnosis, whereas no significant difference was observed in adult AML. Importantly, enormous differences in the genomic landscape in adult compared to pedAML were shown, ${ }^{50,51}$ potentially explaining some of the differential associations observed in our cohorts. The association between TARP expression and a poor prognosis is in agreement with a recent report, investigating the association between transcript expression and clinical outcome in pedAML, ranking TARP within the top genes significantly associated with a detrimental outcome. ${ }^{52}$ To shed light on the link between FLT3-ITD and TARP, mRNA sequencing of the transgenic $\mathrm{OE}$ and $\mathrm{KD}$ cell lines compared to their WT cell line is ongoing. As it was recently shown that the FLT3-ITD regions encode immunogenic, HLA-presented neo-epitopes ${ }^{53}$ the benefit of CTL therapy targeting both leukemogenic molecules in pedAML could be of great interest. On the other hand, CBF leukemias, representing a favorable cytogenetic subgroup, ${ }^{2,8}$ were only present $(P<0.01)$ in the TARP-low group for both pediatric and adult patients. AML cell lines derived from pediatric cases (MV4;11, THP-1) and LSC-enriched cell lines (Kg-1a, HNT-34), showed the highest TARP levels, confirming a relation between TARP, the LSC compartment and pedAML, although also HL-60 (adult, CD34-) showed high expression. Whether TARP remains differentially expressed within LSC outside the predominant CD $34^{+} \mathrm{CD} 38^{-}$compartment, as it does within CD34 $\mathrm{AML}^{15,54}$ needs to be explored further. In addition, we showed that transcripts differ from those in solid tumors and are derived from both the TRGC1 and TRGC2 coding regions. Sequencing analysis indicated the presence of a second, AML-exclusive, TARP transcript encoding TRGC2 instead of TRGC1.

TARP protein expression was in agreement with transcript levels, showing a $15-25 \mathrm{kDa}$ fragment in AML cell lines. In breast and prostate adenocarcinoma, TARP had previously been defined as a $7 \mathrm{kDa}$ protein, ${ }^{42,48}$ although also a $9 \mathrm{kDa}$ fragment was reported in MCF-7. ${ }^{42,48}$ Fritzsche et al. detected protein sizes in prostate carcinoma of $20-25 \mathrm{kDa},{ }^{55}$ comparable to our findings, whereas Yue et al. reported a $15 \mathrm{kDa}$ protein. ${ }^{49}$ Besides its size, the subcellular localization of TARP in AML needs to be refined. qPCR analysis revealed cytoplasmic localization, and confocal microscopy showed sporadic ER overlap, in contrast to previously reported mitochondrial co-localization. ${ }^{43}$ We observed an enrichment of TARP at the cells' protrusions in Kg-1a and sorted leukemic cells. Protrusions are kinetic cytoskeletal abnormalities formed during chemokine-induced cell migration, e.g. homing of CD34 $4^{+}$HSC towards the bone marrow niche. ${ }^{56}$ The presence of molecular abnormalities in $\mathrm{CD}_{34} 4^{+}$progenitor cells was shown to increase protrusion formation. ${ }^{57}$ Indeed, LSC were reported to compete with HSC for endosteal niche engraftment, where they are protected from chemotherapy-induced apoptosis. ${ }^{12,58}$ Whether TARP interferes in homing and chemoprotection of leukemic AML cells in the BM microenvironment needs to be elucidated. Although protein expression was readily up-regulated in TARP transgenic cell lines, shRNA-mediated knockdown appeared to be less efficient. Possible explanations are the presence of escape mechanisms and alternative translation pathways during silencing or a very high stability of the TARP protein, persisting in the cell for a long period of time.

To explore TARP as an immunotherapeutic target in AML, we evaluated the cytokine release and cytotoxic killing capacities of TARP-TCR transgenic CTL in vitro. TARP and HLA-A*0201 co-expressing cell lines were efficiently lysed, and although evaluated on a limited number of patients $(n=5)$, TARP-TCR CTL were able to kill primary leukemic cells with a borderline correlation to the TARP transcript expression. Interestingly, weaker responses were observed for the cognate $\mathrm{TARP}_{4-13}$ peptide, since the TCR is directed against the HLA-A*0201 enhanced affinity TARP(P5L) $)_{4-13}$ peptide. Moreover, pulsed T2 cells appeared to be more susceptible than AML cells. This finding is in agreement with previous data, ${ }^{47,59}$ and several reasons may account for this phenomenon. First, peptide processing, transport and/or MHC-I presentation may be disturbed in leukemic cells. ${ }^{60}$ Second, high and stable HLAA*0201 expression is vital for triggering lytic responses, and transgenic expression might diminish during culture. Therefore, we cannot exclude the possibility that HLA$A^{*} 0201$-mediated TARP presentation within the transgenic OCI-AML3 cell line had diminished during longterm culture. Third, competition between transgenic and endogenous MHC-I molecules might block HLA-A*0201guided peptide presentation. Indeed, the TARP-TCR was shown to suffer from low MHC-I avidity compared to foreign epitope-directed TCR. ${ }^{11}$ Cloning the TARP $_{4 \cdot 13}$-TCR sequence into a retroviral construct enabled higher transduction efficiencies and the generation of mock CTL to correct non-TARP mediated lysis, which are lacking in previous reports. ${ }^{37,49}$ As promoters driving TCR expression differed between constructs, and functional activity is known to correlate with TCR cell-surface expression, ${ }^{62}$ it was no surprised that different killing rates between LV and RV transduced CTL were osberved. In addition, intrinsic reactivity, HLA status and endogenous TCR repertoire of each donor as such might have an impact. ${ }^{62}$ In addition, comparing reactivity by effectors from an allogeneic versus autologous setting will be implemented in future experiments.

In conclusion, we showed that TARP is highly expressed in AML leukemic cells, including the $\mathrm{CD} 34^{+} \mathrm{CD} 38^{-} \mathrm{LSC}$ compartment, while absent in normal counterparts. Moreover, TARP expression was associated with FLT3-ITD in pedAML. We provide in vitro evidence that 
TARP-directed CTL effectively kill TARP and HLA$\mathrm{A}^{*} 0201$ co-expressing cell lines and primary leukemic cells, and thus hold great promise for immunotherapeutic T-cell therapy.

\section{Acknowledgments}

Our gratitude goes to Dr. F. Plasschaert, the staff of the Department of adult Hematology and Pediatric Hematology and Oncology of the Ghent University Hospital (Ghent, Belgium), and C. Matthys of the Cord Blood Bank, for providing samples. The authors thank all patients and their parents for their participation in the study, as well as the data managers involved in the clinical trials. We are indebted to $S$. Vermaut for cell sorting and all technicians of the Childhood Cancer Foundation and
Laboratory of the Ghent University Hospital (Ghent, Belgium). We thank our collaborators from the LL Biology Working Group for their relevant contributions, in particular Prof. Dr. GJ Kaspers for taking interest in our research.

\section{Funding}

This research was supported by the Belgian Foundation against Cancer (grant 2014-265), FOD-KankerPlan (Actie29, grant to JL) and vzw Kinderkankerfonds (grant to TL). The Research Foundation - Flanders (Fonds voor Wetenschappelijk Onderzoek Vlaanderen, FWO) supported TK (grant 1831312N) and BD (grants 1113117 and V433317N). This work is submitted in partial fulfilment of the requirement for the $P h D$ of candidate BD at Ghent University.

\section{References}

1. Dohner H, Estey EH, Amadori S, et al. Diagnosis and management of acute myeloid leukemia in adults: recommendations from an international expert panel, on behalf of the European LeukemiaNet. Blood. 2010;115(3):453-474

2. Dohner H, Estey E, Grimwade D, et al. Diagnosis and management of AML in adults: 2017 ELN recommendations from an international expert panel. Blood. 2017;129(4):424-447.

3. De Kouchkovsky I, Abdul-Hay M. Acute myeloid leukemia: a comprehensive review and 2016 update. Blood Cancer J. 2016; 6(7):e441.

4. Bonnet D, Dick JE. Human acute myeloid leukemia is organized as a hierarchy that originates from a primitive hematopoietic cell. Nat Med. 1997;3(7):730-737.

5. Rasche M, Zimmermann M, Borschel L, et al. Successes and challenges in the treatment of pediatric acute myeloid leukemia: a retrospective analysis of the AML-BFM trials from 1987 to 2012. Leukemia. 2018; 32(10):2167-2177.

6. Creutzig U, van den Heuvel-Eibrink MM, Gibson B, et al. Diagnosis and management of acute myeloid leukemia in children and adolescents: recommendations from an international expert panel. Blood. 2012;120(16):3187-3205.

7. von Neuhoff C, Reinhardt D, Sander A, et al. Prognostic impact of specific chromosomal aberrations in a large group of pediatric patients with acute myeloid leukemia treated uniformly according to trial AMLBFM 98. J Clin Oncol. 2010;28(16):26822689.

8. De Moerloose B, Reedijk A, de Bock GH, et al. Response-guided chemotherapy for pediatric acute myeloid leukemia without hematopoietic stem cell transplantation in first complete remission: Results from protocol DB AML-01. Pediatr Blood Cancer. 2019;66(5):e27605.

9. Meshinchi S, Woods WG, Stirewalt DL, et al. Prevalence and prognostic significance of Flt3 internal tandem duplication in pediatric acute myeloid leukemia. Blood. 2001; 97(1):89-94.

10. Hope KJ, Jin L, Dick JE. Acute myeloid leukemia originates from a hierarchy of leukemic stem cell classes that differ in selfrenewal capacity. Nat Immunol. 2004; 5(7):738-743

11. Shlush LI, Mitchell A, Heisler L, et al.
Tracing the origins of relapse in acute myeloid leukaemia to stem cells. Nature. 2017;547(7661):104-108.

12. Ishikawa F, Yoshida S, Saito $Y$, et al Chemotherapy-resistant human AML stem cells home to and engraft within the bonemarrow endosteal region. Nat Biotechnol. 2007;25(11):1315-1321

13. Thomas D, Majeti R. Biology and relevance of human acute myeloid leukemia stem cells. Blood. 2017;129(12):1577-1585.

14. Griessinger E, Anjos-Afonso F, Pizzitola I, et al. A niche-like culture system allowing the maintenance of primary human acute myeloid leukemia-initiating cells: a new tool to decipher their chemoresistance and self-renewal mechanisms. Stem Cells Transl Med. 2014;3(4):520-529.

15. Ng SW, Mitchell A, Kennedy JA, et al. A 17 gene stemness score for rapid determination of risk in acute leukaemia. Nature. 2016;540(7633):433-437.

16. Terwijn M, Zeijlemaker W, Kelder A, et al. Leukemic Stem Cell Frequency: A Strong Biomarker for Clinical Outcome in Acute Myeloid Leukemia. PLoS One. 2014; 22:9(9):e10758

17. van Rhenen A, Feller N, Kelder A, et al. High stem cell frequency in acute myeloid leukemia at diagnosis predicts high minimal residual disease and poor survival. Clin Cancer Res. 2005;11(18):6520-6527.

18. Hanekamp D, Denys B, Kaspers GJL, et al. Leukaemic stem cell load at diagnosis predicts the development of relapse in young acute myeloid leukaemia patients. Br J Haematol. 2018;183(3):512-516.

19. Witte KE, Ahlers J, Schafer I, et al. High Proportion of Leukemic Stem Cells at Diagnosis Is Correlated with Unfavorable Prognosis in Childhood Acute Myeloid Leukemia. Pediatr Hemat Oncol. 2011;28(2):91-99.

20. Annesley CE, Brown P. The Biology and Targeting of FLT3 in Pediatric Leukemia. Front Oncol. 2014;4:263.

21. Hunger SP, Lu X, Devidas $M$, et al. Improved survival for children and adolescents with acute lymphoblastic leukemia between 1990 and 2005: a report from the children's oncology group. J Clin Oncol. 2012;30(14):1663-1669.

22. Maude SL, Laetsch TW, Buechner J, et al. Tisagenlecleucel in Children and Young Adults with B-Cell Lymphoblastic Leukemia. N Engl J Med. 2018;378(5):439448.

23. Hanekamp D, Cloos J, Schuurhuis GJ
Leukemic stem cells: identification and clinical application. Int $\mathrm{J}$ Hematol. 2017;105(5):549-557.

24. Felipe Rico J, Hassane DC, Guzman ML. Acute myelogenous leukemia stem cells from Bench to Bedside. Cancer Lett. 2013;338(1):4-9.

25. Perna F, Berman SH, Soni RK, et al Integrating Proteomics and Transcriptomics for Systematic Combinatorial Chimeric Antigen Receptor Therapy of AML. Cancer Cell. 2017;32(4):506-519.

26. Pollyea DA, Gutman JA, Gore L, et al Targeting acute myeloid leukemia stem cells: a review and principles for the development of clinical trials. Haematologica. 2014;99(8):1277-1284.

27. Jen EY, Ko CW, Lee JE, et al. FDA Approval: Gemtuzumab Ozogamicin for the Treatment of Adults with Newly Diagnosed CD33-Positive Acute Myeloid Leukemia. Clin Cancer Res. 2018;24(14):3242-3246.

28. Parigger J, Zwaan CM, Reinhardt D, et al Dose-related efficacy and toxicity of gemtuzumab ozogamicin in pediatric acute myeloid leukemia. Expert Rev Anticancer Ther. 2016;16(2):137-146.

29. van Rhenen A, Moshaver B, Kelder A, et al Aberrant marker expression patterns on the CD34+CD38- stem cell compartment in acute myeloid leukemia allows to distinguish the malignant from the normal stem cell compartment both at diagnosis and in remission. Leukemia. 2007;21(8):17001707.

30. Bonardi F, Fusetti F, Deelen P, et al. A proteomics and transcriptomics approach to identify leukemic stem cell (LSC) markers Mol Cell Proteomics. 2013;12(3):626-637.

31. Majetl R, Becker MW, Tian Q, et al Dysregulated gene expression networks in human acute myelogenous leukemia stem cells. Proc Natl Acad Sci U S A. 2009;106(9):3396-3401.

32. Eppert K, Takenaka K, Lechman ER, et al. Stem cell gene expression programs influence clinical outcome in human leukemia. Nat Med. 2011;17(9):1086-1093.

33. Forsberg EC, Passegue E, Prohaska SS, et al Molecular signatures of quiescent, mobilized and leukemia-initiating hematopoietic stem cells. PloS One. 2010;5(1):e8785.

34. Gal H, Amariglio N, Trakhtenbrot L, et al Gene expression profiles of AML derived stem cells; similarity to hematopoietic stem cells. Leukemia. 2006;20(12):2147-2154. 
35. Gentles AJ, Plevritis SK, Majeti R, et al. Association of a leukemic stem cell gene expression signature with clinical outcomes in acute myeloid leukemia. JAMA. 2010;304(24):2706-2715.

36. Saito Y, Kitamura H, Hijikata A, et al. Identification of therapeutic targets for quiescent, chemotherapy-resistant human leukemia stem cells. Sci Transl Med. 2010;2(17):17ra9.

37. de Leeuw DC, Denkers F, Olthof MC, et al. Attenuation of microRNA-126 expression that drives CD34+38- stem/progenitor cells in acute myeloid leukemia leads to tumor eradication. Cancer Res. 2014;74(7):20942105.

38. Hellemans J, Mortier G, De Paepe A, et al. qBase relative quantification framework and software for management and automated analysis of real-time quantitative PCR data. Genome Biol. 2007;8(2):R19.

39. Vandesompele J, De Preter K, Pattyn F, et al. Accurate normalization of real-time quantitative RT-PCR data by geometric averaging of multiple internal control genes. Genome Biol. 2002;3(7):Research0034.

40. van Dongen JJ, Langerak AW, Bruggemann $M$, et al. Design and standardization of PCR primers and protocols for detection of clonal immunoglobulin and T-cell receptor gene recombinations in suspect lymphoproliferations: report of the BIOMED-2 Concerted Action BMH4-CT98-3936. Leukemia. 2003:17(12):2257-2317.

41. Essand M, Vasmatzis G, Brinkmann U, et al. High expression of a specific T-cell receptor gamma transcript in epithelial cells of the prostate. Proc Natl Acad Sci U S A. 1999;96(16):9287-9292.

42. Wolfgang CD, Essand M, Vincent IJ, Lee B, Pastan I. TARP: A nuclear protein expressed in prostate and breast cancer cells derived from an alternate reading frame of the $\mathrm{T}$ cell receptor gamma chain locus. Proc Natl Acad Sci U S A. 2000;97(17):9437-9442.

43. Maeda $\mathrm{H}$, Nagata $\mathrm{S}$, Wolfgang $\mathrm{CD}$, et al. The $\mathrm{T}$ cell receptor gamma chain alternate reading frame protein (TARP), a prostatespecific protein localized in mitochondria. J
Biol Chem. 2004:279(23):24561-24568.

44. Oi C, Jia X, Lu L, et al. HEK293T Cells Are Heterozygous for CCR5 Delta 32 Mutation. PloS One. 2016;11(4):e0152975.

45. Lefranc MP, Forster A, Rabbitts TH. Genetic polymorphism and exon changes of the constant regions of the human T-cell rearranging gene gamma. Proc Natl Acad Sci U S A. 1986;83(24):9596-9600.

46. Carlsson B, Totterman TH, Essand M Generation of cytotoxic $\mathrm{T}$ lymphocytes specific for the prostate and breast tissue antigen TARP. Prostate. 2004;61(2):161-170

47. Hillerdal V, Nilsson B, Carlsson B, et al. T cells engineered with a $\mathrm{T}$ cell receptor against the prostate antigen TARP specifically kill HLA-A2+ prostate and breast cancer cells. Proc Natl Acad Sci U S A. 2012; 109(39):15877-15881.

48. Wolfgang CD, Essand M, Lee B, et al. T-cell receptor gamma chain alternate reading frame protein (TARP) expression in prostate cancer cells leads to an increased growth rate and induction of caveolins and amphiregulin. Cancer Res. 2001; 61(22):8122-8126.

49. Yue H, Cai Y, Song Y, et al. Elevated TARP promotes proliferation and metastasis of salivary adenoid cystic carcinoma. Oral Surg Oral Med Oral Pathol Oral Radiol. 2017;123(4):468-476.

50. Farrar JE, Schuback HL, Ries RE, et al. Genomic profiling of pediatric acute myeloid leukemia reveals a changing mutational landscape from disease diagnosis to relapse. Cancer Res. 2016;76(8):2197-2205.

51. Bolouri H, Farrar JE, Triche $T$, et al. The molecular landscape of pediatric acute myeloid leukemia reveals recurrent structural alterations and age-specific mutational interactions. Nat Med. 2017;24(1):103112.

52. Lamba JK, Cao X, Raimondi SC, et al Integrated epigenetic and genetic analysis identifies markers of prognostic significance in pediatric acute myeloid leukemia. Oncotarget. 2018;9(42):26711-26723.

53. Graf C, Heidel F, Tenzer S, et al. A neoepitope generated by an FLT3 internal tandem duplication (FLT3-ITD) is recognized by leukemia-reactive autologous CD8+ T cells. Blood. 2007;109(7):2985-2988.

54. Quek L, Otto GW, Garnett C, et al. Genetically distinct leukemic stem cells in human CD34- acute myeloid leukemia are arrested at a hemopoietic precursor-like stage. J Exp Med. 2016;213(8):1513-1535.

55. Fritzsche FR, Stephan C, Gerhardt J, et al Diagnostic and prognostic value of $\mathrm{T}$-cell receptor gamma alternative reading frame protein (TARP) expression in prostate cancer. Histol Histopathol. 2010;25(6):733739.

56. van Buul JD, Voermans C, van Gelderen J, et al. Leukocyte-endothelium interaction promotes SDF-1-dependent polarization of CXCR4. J Biol Chem. 2003;278(32):3030230310.

57. Salgia R, Li JL, Ewaniuk DS, et al. BCR/ABL induces multiple abnormalities of cytoskeletal function. J Clin Invest. 1997; 100(1):46-57.

58. Boyd AL, Campbell CJV, Hopkins CI, et al Niche displacement of human leukemic stem cells uniquely allows their competitive replacement with healthy HSPCs. J Exp Med. 2014;211(10):1925-1935.

59. Oh S, Terabe M, Pendleton CD, et al Human CTLs to wild-type and enhanced epitopes of a novel prostate and breast tumor-associated protein, TARP, lyse human breast cancer cells. Cancer Res. 2004;64(7):2610-2618.

60. Coulie PG, Van den Eynde BJ, van der Bruggen $P$, et al. Tumour antigens recognized by $T$ lymphocytes: at the core of cancer immunotherapy. Nat Rev Cancer. 2014 14(2):135-146.

61. Hillerdal V, Boura VF, Bjorkelund $\mathrm{H}$, et al Avidity characterization of genetically engineered T-cells with novel and established approaches. BMC Immunol. 2016;17(1):23.

62. Heemskerk MH, Hagedoorn RS, van der Hoorn MA, et al. Efficiency of T-cell receptor expression in dual-specific $T$ cells is controlled by the intrinsic qualities of the TCR chains within the TCR-CD3 complex. Blood. 2007;109(1):235-243. 